\title{
Inclusão escolar e deficiência mental: análise da interação social entre companheiros
}

\author{
Marcus Welby Batista \\ Sônia Regina Fiorim Enumo \\ Universidade Federal do Espírito Santo
}

\begin{abstract}
Resumo
A inclusão escolar de portadores de deficiências tem sido a proposta norteadora e dominante na Educação Especial no Brasil nos últimos anos. Esta pesquisa teve por objetivo descrever e analisar a interação social entre três alunos das primeiras séries do Ensino Fundamental com Deficiência Mental (DM) e seus colegas, em três escolas-pólos municipais de Vitória, ES. Aplicaram-se a todos 80 alunos testes sociométricos com perguntas sobre três escolhas e três rejeições para brincar e realizar tarefas escolares; foram filmadas 15 sessões de observações na situação de recreio, cinco para cada um dos três sujeitos focais. Esses dados foram compatíveis com aqueles obtidos nos testes sociométricos, mostrando que esses os alunos com DM são menos aceitos e são mais rejeitados do que seus colegas, passando a maior parte do tempo de recreio sozinhos, demonstrando dificuldades para iniciar, manter e finalizar os contatos sociais com os colegas.
\end{abstract}

Palavras-chave: interação entre companheiros; inclusão escolar; deficiência mental

\begin{abstract}
School inclusion and mental deficiency: analysis of the social interaction among peers. The inclusion of bearers of deficiencies in schools has been a guiding and dominating proposal in Special Education, including in Brazil, and has directed rehabilitation and educational programs and policies. The aim of this study was to describe and to analyze the interaction among three students with Mental Retardation (MR) and their peers. The study was carried out with first-grade students of three core municipal schools of the city of Vitória, ES, Brazil, who had classmates who were bearers of MR. All 80 students were given a sociometric test containing questions on three choices and rejections of classmates with whom to play and to accomplish classroom tasks. Fifteen observation sessions were recorded, five for each target children (plus an extra one for one of the children), during an entire month. The results showed that students who have special education needs are less frequently accepted and more frequently rejected than their peers in regular classrooms. It was noted that subjects spent most of their time alone, showing difficulties in initiating, maintaining and finalizing contacts with their classmates.
\end{abstract}

Key words: peers interaction; school inclusion; mental deficiency

A integração dos portadores de deficiências tem sido a proposta norteadora e dominante na Educação Especial, direcionando programas e políticas educacionais e de reabilitação em vários países, incluindo-se o Brasil (Cardoso, 1992; Carvalho, 1994; Glat, 1998; Mantoan, 1997).

Historicamente, a proposta de integração escolar foi elaborada em 1972, na Educação Especial, por um grupo de profissionais da Escandinávia, liderados por Wolfensberger, na forma do chamado princípio de normalização. Este princípio apregoa que todas as pessoas portadoras de deficiências têm o direito de usufruir de condições de vida o mais comum ou "normal” possível, na sociedade em que vivem. Dito de outra forma, normalizar não quer dizer tornar normal, significa dar à pessoa oportunidades, garantindo seu direito de ser diferente e de ter suas necessidades reconhecidas e atendidas pela sociedade.

Assim, o conceito de integração é uma das conseqüências fundamentais do princípio de normalização: “Normalização é objetivo. Integração é processo. Integração é fenômeno complexo que vai muito além de colocar ou manter excepcionais em classes regulares” (Pereira, 1990). É, portanto, parte fundamental de todo o processo educacional.

Essas noções de normalização e integração se difundiram rapidamente nos Estados Unidos da América, Canadá e por diversos países da Europa, fortalecendo-se, no final dos anos 60 e início dos anos 70 do século XX, junto com os movimentos de direitos civis, quando diversas minorias e grupos marginalizados começaram a lutar para conquistar seu 
espaço na sociedade (Glat, 1998; Saint-Laurent, 1997). Também no Brasil, a filosofia da integração parece dominar não apenas a atitude teórica dos profissionais da área (Aranha, 1994; Cardoso, 1992; Figueiredo, 1990; Glat,1989; Jannuzzi,1992; Nunes \& Santos, 1988; Omote, 1994), mas também as propostas de atendimento de diferentes tipos de instituições (Arns, 1992; Carvalho, 1989; Mantoan, 1988; Mendes, 1994; Pereira, 1990). Da mesma forma o faz a política do governo para a educação, em nível nacional, pela Constituição de 1988, art. 208, parágrafo III (Brasil, 1988), no âmbito do Estado do Espírito Santo, pela Constituição Estadual de 1989, art. 171, e em nível municipal da capital do Espírito Santo (Secretaria Municipal da Educação de Vitória, 1999).

Tendo como ponto de partida os resultados positivos alcançados com a prática da inclusão escolar nos países desenvolvidos, nas duas últimas décadas, o sistema educacional brasileiro tem vivenciado um momento de transição no atendimento dos alunos com necessidades educativas especiais. De um lado, havia um modelo de educação especial que adotava as classes especiais para alunos com necessidades educativas especiais, propondo-se a um atendimento mais específico (Mazzota, 1982). Na medida em que esse modelo contribuía para segregação dessas crianças, a inclusão escolar ganhou força, refletindo os esforços atuais das sociedades pela sua integração em salas regulares de ensino, de forma a aceitar e respeitar suas diferenças (Bueno, 1991; Glat, 1989). A partir do final dos anos 80 do século $X X$, o termo integração começou a perder força, sendo substituído pela idéia de inclusão, uma vez que o objetivo é incluir, sem distinção, todas as crianças, independentemente de suas habilidades.

Cabe aqui uma maior especificação das palavras integração e inclusão na área escolar, uma vez que ambas priorizam a inserção da pessoa com necessidades educacionais especiais na escola regular (Thomas, Walker \& Webb, 1998). A palavra inclusão remete-nos a uma definição mais ampla, indicando uma inserção total e incondicional. Integração, por sua vez, dá a idéia de inserção parcial e condicionada às possibilidades de cada pessoa, já que o pressuposto básico é de que a dificuldade está na pessoa portadora de deficiência, e que estas podem ser incorporadas no ensino regular sempre que suas características permitirem. Dito de outra forma, a inclusão exige a transformação da escola, pois defende a inserção no ensino regular de alunos com quaisquer déficits e necessidades, cabendo às escolas se adaptarem às necessidades dos alunos, ou seja, a inclusão acaba por exigir uma ruptura com o modelo tradicional de ensino (Werneck, 1997). A noção de inclusão, por essa razão, não estabelece parâmetros (como faz o conceito de integração) em relação a tipos particulares de deficiências.

Sassaki (1998) faz uma outra distinção, conceituando a integração enquanto inserção do deficiente preparado para conviver na sociedade, e a inclusão como uma mudança sine qua non na sociedade, para que a pessoa portadora de deficiência possa se desenvolver e exercer a cidadania.

Resumindo, a integração privilegia o aluno portador de necessidades educativas especiais, dividindo com ele a responsabilidade da inserção, enquanto a inclusão tenta avançar, exigindo também da sociedade, em geral, condições para essa inserção. Em outros termos, a integração é um tanto mais "individualizada" e a inclusão um tanto mais "coletiva”. Na prática inclusiva, no entanto, percebe-se que mesmo aqueles alunos que se encontram inseridos no sistema regular de ensino continuam sendo isolados dos seus companheiros de turma não-deficientes (Gresham, 1982; Siperstein, Leffert, \& Widaman, 1996).

Pesquisadores da área de interação social têm identificado que estudantes rejeitados socialmente interagem diferentemente, com agressividade, rejeição e ignoram outros alunos, com mais freqüência do que com os estudantes aceitos socialmente. Como resultado, estudantes com deficiências severas têm pouca oportunidade de praticar, refinar e expandir os seus repertórios de competência social, tendo, assim, reduzida a probabilidade de desenvolver amizades. O significado desses achados repousa no fato de que a competência social em crianças é preditora dos ajustamentos futuros (Kupersmidt, Coie, \& Dodge, 1990; Meyer, Cole, McQuarter, \& Reicchle,1990).

A importância dos companheiros de brincadeiras na socialização de crianças é de fundamental importância e os estudos feitos nas áreas de Psicologia Social e do Desenvolvimento a têm reforçado (Harris, 1995, 1999). Uma das mais recentes e completas revisões sobre o processo de socialização de crianças e adolescentes foi elaborada por Harris (1995, 1999), mostrando que os pais não são os principais protagonistas na determinação da personalidade adulta de seus filhos, apesar de serem os principais agentes socializadores, aqueles que mais precocemente atuam sobre a criança. Não sendo os pais os únicos e nem os principais agentes influenciadores de seus filhos, afirma-se a importância do grupo no processo de socialização. De acordo com a teoria da socialização de grupo de Harris (1999): “(...) as crianças se identificam com um grupo constituído dos pares delas, que talham o comportamento delas às normas do grupo e que os grupos contrastam com outros grupos e adotam normas diferentes” (p.335).

Harris $(1995,1999)$ explica que o processo de formação de grupo se apóia na capacidade inata do homem possuir cérebro construído com a habilidade de classificar, categorizar, nomear, rotular ou dividir pessoas ou coisas em grupo; capacidade esta já observada em outras espécies e na criança antes de um ano de idade, que já faz categorizações por idade e sexo. A terceira forma de classificação usada pelo homem é a raça, que leva mais tempo para ser adquirida.

Esse processo de categorização, por sua vez, independe da existência de rótulos, pois uma categoria se define por um conceito, que pode existir mesmo sem um nome. Assim, para que ocorra uma condição de grupo não é preciso haver uma história anterior de amizade, um conflito com membros de outro grupo, a luta por território, saber quem são seus companheiros, nem mesmo existirem diferenças visíveis na aparência ou no comportamento.

É claro que ter características como sociabilidade, amabilidade e beleza afeta o relacionamento com mãe, pai, profes- 
sores e seus pares. Entretanto, sentir-se membro de um grupo ou fazer uma autocategorização, segundo Turner (1987, citado por Harris, 1995, 1999), independe dessas condições. A autocategorização é fortemente dependente do contexto social - onde estamos e quem está conosco - e varia de um momento para outro em função da saliência das várias categorias sociais. Por exemplo, a categoria social criança não se destaca quando só há crianças no ambiente, mas sim meninos e meninas, ou crianças mais novas e mais velhas. De acordo com Turner (1984): “As auto-imagens que assumimos representam a produção cognitiva da autocategorização, que é altamente variável e específica para a situação” (p. 527).

Dessa forma, não são as relações próximas que fazem alguém pertencer a um grupo, mas o grupo com o qual se identifica; o grupo de referência ou grupo psicológico é o que conta. O processo básico de formação do grupo não está centrado na atração nem na interdependência, mas, sim, na identificação. Afiliar-se a grupos acarreta a reação eles gostam de mim, gosto deles - a percepção de que somos semelhantes de algum modo aos outros membros do grupo, que há algo em comum entre nós. Assim, as diferenças dentro do grupo tendem a diminuir (assimilação), enquanto as diferenças entre os grupos humanos aumentam (contraste de grupo). Essa é uma das conseqüências do processo de categorização: "ela [a categorização] nos faz ver os itens dentro de uma categoria como sendo mais semelhantes do que eles realmente são. Ao mesmo tempo, ela nos faz ver itens de categorias diferentes como mais diferentes do que realmente são” (Harris, 1999, p. 175-176, grifo da autora).

Para manter a identidade e a coesão do grupo, as crianças usam diversos métodos, às vezes cruéis - aquelas que não se conformam ou não podem se conformar com as regras explícitas e não-explícitas podem ser excluídas, criticadas ou ridicularizadas. Surgem, assim, os bobos ou palhaços do grupo, devido à pressão por conformidade, que é mais intensa na infância do que na adolescência (Harris, 1999). O estereótipo, traduzido no apelido, passará a identificar a criança pelo grupo, que se apóia em qualquer idiossincrasia de aparência, jeito, habilidade ou qualquer outro aspecto da criança, para mostrar a hierarquia de dominação.

Assim, os contrastes intra e intergrupos existem sem quaisquer diferenças reais; os próprios grupos as criam. Basta uma ameaça em comum para o grupo se unir, tratando o diferente ou estrangeiro com desconfiança e medo, que se transformam depois em hostilidade, pois ter medo é desagradável. Reside aqui o grande poder emocional do grupo, resultado de uma longa história evolutiva de sobrevivência dependente do grupo de parentesco (Harris, 1995, 1999).

Esse processo serve de base para o acasalamento e para a amizade. Bons amigos, nos primeiros anos escolares, por exemplo, são provavelmente da mesma idade, mesmo sexo e mesma raça, com interesses e valores semelhantes. De outro lado, a falta de interação entre companheiros, embora rara, pode ocorrer para pessoas criadas em fazendas isoladas ou que ficaram presas em casa por distúrbios físicos crônicos ou mesmo para crianças-prodígios, levando essas pessoas a um alto risco de distúrbios psicológicos quando adultas, alerta Harris (1995, 1999). O adequado desenvolvimento da personalidade e da aprendizagem da língua dependem, então, da criança ser exposta a seus companheiros de brincadeiras. Por imitação e por observação, as crianças aprendem não só com seus pais, com a televisão e livros de histórias, mas principalmente em brincadeiras de faz-de-conta, tanto que os modelos preferidos de crianças escolares são outras crianças (Harris, 1999).

Como se vê, existe um número considerável de razões para explanar a relevância a respeito do brincar e seu papel no decorrer do desenvolvimento infantil. Para Morin (1979), o brincar pode ser entendido como um prolongamento da infância na qual a criança encontra-se ainda protegida e cuidada, tendo mais tempo para desenvolver habilidades necessárias para a vida adulta.

Brincar com companheiros, entretanto, é uma habilidade que precisa de tempo para se desenvolver. Com um ano de idade, as crianças brincam lado-a-lado, desajeitadamente; aos dois anos, já são capazes de uma imitação mais elaborada, divertindo-se com brincadeiras do tipo Faça o que o chefe mandar; com dois anos e meio já recorrem ao uso de palavras e ações para coordenar as brincadeiras, desempenhando papéis diferentes nessas fantasias compartilhadas. Entre um e três anos, já construíram modelos de relações com companheiros, escolhendo de quem gostar. Observamos, assim, desde o maternal, a existência de "panelinhas" de crianças com a mesma idade e mesmo sexo, especialmente aos cinco anos (Harris, 1999).

Diante do exposto, pressupõe-se que a proposta de inclusão escolar de crianças com necessidades educativas especiais procura evitar os efeitos deletérios do isolamento social dessas crianças, criando oportunidades para a interação entre as crianças, inclusive como forma de diminuir o preconceito.

Uma vez que as crianças tomam para si as normas do grupo, é interessante estudar a presença de alunos com deficiência no ambiente regular de ensino, assim como as interações sociais que ocorrem naturalmente entre alunos com deficiência e os demais, focalizando o papel do outro como mediador de sua interação com a sociedade.

Na medida em que a área cognitiva do desenvolvimento de crianças classificadas como portadoras de deficiência mental é considerada a mais crítica ou defasada em relação às crianças ditas "normais”, é relevante conhecer também as relações existentes entre o desenvolvimento cognitivo e o processo de interação social.

De outro lado, a carência de instrução leva a uma falta de aprendizagem, até mesmo de habilidades sociais, alertam Strain e Shores (1983). A avaliação de habilidades sociais em ambiente segregado não é conveniente, pois subestima o desempenho da criança, dada a qualidade recíproca do comportamento social. Além do mais, essas habilidades sociais, aprendidas no contexto segregador, não poderão ser generalizadas para um contexto integrado. Saint-Laurent (1997) explica esse processo com base em conceitos sócio- 
construtivistas, os quais sugerem que: "mantida em um estado de isolamento social, a criança não poderá desenvolver as funções sociais superiores. Para isso, ela necessita estabelecer interações sociais com um profissional especializado, estabelecer relações com seus colegas/companheiros”. (p. 6869)

Deduz-se, a partir desses estudos, que o processo de inclusão/integração de crianças com deficiência no ensino regular possibilita-lhes interagir espontaneamente em situações diferenciadas, enquanto adquirem conhecimento e se desenvolvem. Essa integração, entretanto, não deve ser facilmente resolvida a partir de uma resolução de cunho legal ou teórica, uma vez que variáveis relacionadas a processos grupais e reações de preconceito podem influenciá-la, seja facilitando ou dificultando a integração dessas pessoas com aquelas ditas “normais”. Por exemplo, são conhecidos os casos de pais que tiram suas crianças de escolas que aceitam alunos “diferentes" por medo de "contágio” ou rebaixamento do nível de aprendizagem de seus filhos. Pode-se questionar, a partir desse exemplo corriqueiro, se as próprias crianças “normais” não teriam uma reação ao estranho. Ou se ajudariam seu novo e diferente colega movidos por sentimentos de piedade ou compaixão. Podemos pensar também em como ocorreriam suas interações fora do controle da professora em sala de aula, no recreio.

Assim, foi considerada relevante a análise de como essas crianças estão sendo aceitas por seus pares, o estudo de suas próprias verbalizações, acrescido de observações das suas interações sociais fora do contexto de sala de aula. Pretendeu-se, então, estudar de modo mais sistemático como ocorrem essas interações sociais entre a criança com necessidades educativas especiais decorrente de um quadro de deficiência mental, incluída no ensino regular, analisando e observando seu comportamento e de seus colegas na situação de recreio.

\section{Método}

\section{Participantes e locais de coleta de dados}

Participaram desta pesquisa três alunos portadores de deficiência mental e seus colegas de classe de ensino regular do Bloco Único Inicial, correspondente a primeira e segunda séries do Ensino Fundamental, localizados em três das nove escolas-pólo da Rede Municipal de Educação de Vitória, ES, consideradas como local mais adequado e representativo para estudo devido a sua destinação oficial para esse tipo de serviço educacional.

A caracterização dos alunos deficientes mentais foi realizada a partir de informações escritas e verbais obtidas com membros da equipe que atendia esses alunos e a partir de laudos psicopedagógicos emitidos pela Secretaria Municipal de Educação de Vitória, ES.

Tendo por objetivo acompanhar o possível desenvolvimento de interações sociais desses alunos com seus colegas no ambiente inclusivo, foram registrados os comportamentos dos alunos no pátio de recreio de três escolas públi- cas. A permanência de todos os alunos no recreio era de aproximadamente 20 minutos diários, divididos entre o refeitório e o tempo livre no pátio.

\section{Material}

Para detectar as redes sociais já estabelecidas entre os alunos e a organização social do grupo, foi construída uma escala sociométrica, com base nas fotos dos alunos de cada classe. Foi utilizada também uma filmadora para registro da interação social dos alunos no recreio.

\section{Procedimento}

A aplicação do teste sociométrico seguiu o procedimento descrito a seguir.

Visando a obtenção de um retrato da organização do grupo de alunos após um maior tempo possível de exposição social entre eles, ou seja, após alguns meses de convivência em classe escolar, foi aplicada uma escala sociométrica. Foi pedido a cada aluno, individualmente, que olhasse fotos de colegas da sua classe e apontasse ou nomeasse três colegas com quem gostaria de trabalhar em sala de aula e com quem gostaria de brincar no recreio. Depois dessa nomeação positiva, foi solicitado que fizesse seis outras nomeações, negativas, indicando três colegas com os quais não gostaria de fazer trabalhos em sala de aula e outros três colegas com os quais não gostaria de brincar no recreio.

Considerando que a situação de recreio-livre permite a ocorrência de comportamentos interativos mais espontâneos por parte dos alunos, aumentando, assim, as possibilidades de se observar suas preferências e rejeições sociais em situação natural, foram realizadas cinco sessões de observação para cada aluno-alvo, na situação de recreio, ao longo de um mês. Dezesseis sessões (quinze planejadas originalmente e uma extra) foram gravadas em vídeo-tape, focalizando como aluno-alvo aquele com necessidades educativas especiais-DM, durando, em média, 20 minutos cada uma (tempo médio destinado ao recreio pela escola), totalizando 186 minutos e 16 segundos de gravação. Convém esclarecer que o aluno-alvo A1 teve uma sessão a mais de filmagem para podermos manter a média de tempo filmado e isso foi devido a alguns dias o recreio ter tido menor duração.

\section{Processamento dos dados}

\section{a) dados sociométricos}

As informações obtidas com o teste sociométrico foram organizadas na forma de uma tabela de apuração, matriz sociométrica ou sociomatriz, cujos dados foram representados num mapa denominado sociograma, que revela a posição social relativa de cada pessoa no grupo (Lima, 1969; Monteiro, 1993; Silva, 1979). Foi possível, assim, representar a situação de cada aluno-alvo em relação aos seus colegas, na forma de uma "roda" - que consiste de uma série de linhas circulares concêntricas, cada uma representando as áreas I, II, III e IV, de dentro para fora, respectivamente de 75-100\%, de $50-75 \%$, de $25-50 \%$ e de $0-25 \%$ da escolha máxima alcançada pelos alunos da turma, a começar do centro pelo aluno mais 
votado e terminando na periferia com os que não obtiveram nenhum voto. O símbolo do aluno ou alunos que não obtiveram nenhuma escolha foi inscrito sobre a circunferência mais externa, onde ficam os esquecidos (alunos que recebem um pequeno número de votos, que parecem ser ignorados pela maioria do grupo); os alunos inscritos na circunferência mais externa são os isolados (alunos que, embora participem do dia-a-dia escolar, não recebem nenhum voto) e os do centro são os mais populares ou estrelas (grande número de votos; têm ampla rede de relações, são centros de atenção); os rejeitados são aqueles alunos que recebem votos negativos. Evidenciam-se, assim, as estruturas sociométricas, que constituem a análise e interpretação do sociograma (Bonow, 1972).

\section{b) dados obtidos com as filmagens focais}

A análise das filmagens focais foi feita com base no sistema de categorias elaborado por Aranha (1991), com algumas mudanças feitas para melhor se adequar a esta pesquisa. As informações obtidas em vídeo (tomadas focais) foram processadas da maneira descrita a seguir. As fitas foram transcritas cursivamente; fez-se um recorte, primeiramente, de acordo com a ocorrência/não ocorrência de episódios de contato social, de forma a obter uma distribuição temporal das atividades do aluno-focal. Foram utilizados, como medida, percentuais do tempo total de registro; foi caracterizado o contato social (diádico ou poliádico), separando os tipos de parceiros envolvidos (professora ou colegas) no caso de contatos diádicos. Esses episódios interativos foram classificados de acordo com três dimensões descritivas, a saber: (a) duração, (b) tipo/modalidade de interação e (c) conteúdo do contato social; classificaram-se os episódios quanto à identidade do iniciador e do interruptor e à forma de iniciação e interrupção de ambos. Os períodos em que não se detectou contato social foram identificados como sozinho e descritos em termos das atividades desempenhadas pelo aluno, medido através de percentuais de tempo, em segundos.

\section{Sistema de análise das filmagens focais}

As categorias de interação social foram organizadas em: (a) medidas de distribuição temporal, em porcentagem, e (b) medidas de freqüência, e feito o cálculo da duração do contato social, o seu conteúdo, a iniciação e a interrupção do contato social. Foram utilizadas, também, categorias definidas por outros autores (Batista, 1980; Piotto \& Rubiano, 1999), que completaram o sistema proposto por Aranha (1991).

\section{Resultados}

Para iniciar a análise dos dados, foram identificadas as atividades desenvolvidas pelos alunos focais no tempo livre de recreação. A Tabela 1 apresenta a distribuição do número de sessões focais realizadas para cada aluno, o tempo total dessas sessões e o tempo gasto em cada atividade: sozinho ou em interação: interação diádica - interação diádica aluno-professor (A - P) e em interação diádica aluno-colega (A - C) - interação poliádica.

Há, na Tabela 1, uma descrição geral das 15 sessões de gravação, com duração média de 11 minutos cada, equivalendo ao total de três horas de gravação analisadas. Dessas três horas, cerca de uma hora corresponde ao tempo em que os alunos focais estavam sozinhos, sem interagir com os colegas (1.384 segundos em média/aluno, equivalendo à média de 23 minutos/ aluno). As interações diádicas foram mais freqüentes: em média, 13 minutos/aluno, contra a média de sete minutos/aluno em interações poliádicas, estas envolvendo de dois a cinco colegas.

Foram analisados 155 episódios interativos (51,6\%/ aluno, em média), equivalendo à média de 9,4 episódios/sessão. Cada episódio teve a duração média de 24 segundos, caracterizando-se como cadeias de contato. Com o aluno 2 os episódios tiveram uma duração média maior (34 segundos) e o aluno 1 teve um maior número médio de episódios/ sessão.

Tabela 1

Caracterização temporal das condições vivenciadas pelos alunos focais, no recreio escolar

\begin{tabular}{|c|c|c|c|}
\hline Caracterização da interação & A1 & $\mathrm{A} 2$ & $\mathrm{~A} 3$ \\
\hline Sozinho & $36 \mathrm{~min} 28 \mathrm{~s}$ & $32 \mathrm{~min} 46 \mathrm{~s}$ & $54 \mathrm{~min} 15 \mathrm{~s}$ \\
\hline Em interação & $27 \min 23 \mathrm{~s}$ & $24 \mathrm{~min} 16 \mathrm{~s}$ & $9 \min 53 \mathrm{~s}$ \\
\hline Poliádica & $12 \mathrm{~min} 19 \mathrm{~s}$ & $5 \min 24 \mathrm{~s}$ & $4 \min 37 \mathrm{~s}$ \\
\hline Diádica & $15 \mathrm{~min} 04 \mathrm{~s}$ & $18 \mathrm{~min} 52 \mathrm{~s}$ & $5 \min 16 \mathrm{~s}$ \\
\hline diádica Aluno/Professora & $7 \min 19 s$ & $58 \mathrm{~s}$ & - \\
\hline diádica Aluno/Colega & $7 \min 45 \mathrm{~s}$ & $17 \mathrm{~min} 54 \mathrm{~s}$ & $5 \min 16 s$ \\
\hline Tempo total de registro & $63 \mathrm{~min} 51 \mathrm{~s}$ & $57 \mathrm{~min} 2 \mathrm{~s}$ & $64 \mathrm{~min} 23 \mathrm{~s}$ \\
\hline Outras caracterizações & A1 & A2 & $\mathrm{A} 3$ \\
\hline № de sessões & 6 & 5 & 5 \\
\hline Tempo médio/sessões & $10 \mathrm{~min}$ & $11 \mathrm{~min}$ & $12 \mathrm{~min}$ \\
\hline № de episódios interativos & 82 & 42 & 31 \\
\hline Média de episódios/sessão & 13,66 & 8,64 & 6,2 \\
\hline Tempo médio dos episódios & $20 \mathrm{~s}$ & $34,6 \mathrm{~s}$ & $19,1 \mathrm{~s}$ \\
\hline
\end{tabular}


A Tabela 2 resume os principais dados obtidos com as filmagens focais, possibilitando a comparação dos dados quanto aos tipos e conteúdos da interação, bem como as formas de iniciação e interrupção dos episódios interativos. Foi indicada também a classificação obtida nos testes sociométricos.

De posse desses dados, obtidos com as observações e os testes sociométricos, pôde-se caracterizar cada aluno em termos de sua interação com os colegas, visando demonstrar as possibilidades desses instrumentos e suas contribuições para o estudo do processo de inclusão escolar de crianças com deficiência mental.

\section{Aluno 1}

A1 era um menino de 7 anos, com um quadro de dificuldade de linguagem, comunicando-se por gestos e poucas palavras; tinha epilepsia, dificuldades de atenção e concentração, hiperatividade e dificuldade de aprendizagem escolar. Recebeu, assim, o diagnóstico de retardado mental, pela escola. Era egresso de escola particular, na qual fez a educação infantil, estando, na época da coleta de dados, em uma classe com 22 alunos (11 meninos e 11 meninas), com idade entre 6 e 9 anos.

Na avaliação sociométrica, A1 foi identificado como rejeitado, por não ter sido escolhido por nenhum dos 22 colegas e ser rejeitado por dois deles. Estes últimos alegaram não gostar de sua falta de habilidade social (aproximar-se e tirar objeto) e de seu baixo desempenho escolar, motivos pelos quais não o queriam como parceiro nas tarefas escolares. Para brincar, não foi escolhido nem rejeitado, classificandose como esquecido pela turma.

Durante as cinco sessões de observação no recreio (63 minutos e 51 segundos), A1 permaneceu 57,1\% do tempo sozinho, olhando para o ambiente, sem qualquer ponto fixo; outra parte do tempo (20,7\%) ficou vagando pelo pátio.

Quando A1 interagiu (42,8\% do tempo), era com a professora (26 dos 82 episódios), que ficava pajeando-o; ou então, interagia com os colegas, geralmente em díade. Seus episódios interativos duravam, em média, 20 segundos (cadeias de contato), em que, basicamente, ficava conversando com a professora, que além de cuidar, repreendeu-o em seis episódios, por interromper o lanche dos colegas e/ou atrapalhar o jogo das crianças mais velhas.

Os colegas não brincaram com A1. Os contatos sociais foram iniciados, a maioria das vezes (42,6\%), pelas outras crianças que se aproximavam e tocavam em A1. A professora iniciava contatos com ele aproximando-se e verbalizando (39,4\%) ou segurando-o pelo braço $(39,1 \%)$.

Os poucos episódios interativos que ocorreram foram interrompidos pelo próprio A1 (46,3\%), que se virava e se afastava do colega $(48,7 \%)$ ou saía andando (36,6\%). Os colegas interrompiam o contato (39\% dos episódios) simplesmente se afastando de perto dele $(72,4 \%)$ ou virando-se e olhando em outra direção (17,2\%).

Os dados de observação foram coerentes com aqueles obtidos no teste sociométrico, indicando que A1 pouco interagia ou iniciava contatos com os colegas. Estes, por sua vez, demonstraram não ter interesse em brincar ou fazer tarefas escolares com A1.

\section{Aluno 2}

A2 era um menino de 8 anos, com dificuldades para observar, classificar e ordenar, sendo classificado como deficiente mental pela avaliação da escola; tinha limitações físicas dada uma baixa tonicidade muscular. Estava na $1^{\underline{a}}$ série com 27 alunos (13 meninas e 14 meninos), com idade entre 7 e 14 anos. Havia em sua classe outros dois outros alunos diagnosticados como portadores de necessidades educativas especiais.

Na avaliação sociométrica, A2 foi identificado como companheiro, por ter sido escolhido positivamente por seis colegas para fazer tarefas escolares. Para brincar, A2 foi escolhido por sete colegas, situando-se entre os populares dentro da turma.

Durante as cinco sessões de observação no recreio (57 minutos e 2 segundos), A2 permaneceu 57,4\% (32 minutos e 46 segundos) do tempo sozinho, sentado olhando para o ambiente, sem ponto específico. Quando interagiu (42,5\% do tempo), foi com colegas (40 episódios), geralmente em díade. Seus episódios interativos duraram, em média 34,6 segundos (cadeias de contato), em que, basicamente, ficava conversando com os colegas Estes, além do contato físico, cuidaram de A2 durante 11 episódios de um total de 42. Vale ressaltar que a professora, por vezes, encarregou um colega de cuidar de A2. Teve como parceira mais constante uma menina, que além, de auxiliá-lo, brincou com ele em três episódios. Dessa forma, os contatos foram iniciados, na maior parte pelas outras crianças (66,6\%), que aproximavam e conversavam (39,2\%) e aproximavam-se e tocavam em A2 (39,2\%).

Os episódios interativos foram interrompidos, em sua maior parte, pelos colegas (71,4\%), que viravam e abandonavam A2 (46,6\%) e viravam e olhavam em outra direção (20\%). A2 interrompia o contato (23,8\%), virando-se e olhando em outra direção (50\%) ou levantando-se e caminhando para outro lugar (30\%).

Os dados da observação não se mostraram coerentes com aqueles obtidos no teste sociométrico, indicando que A2 tinha pouca iniciativa e que não sustentava os contatos com os colegas. Estes, por sua vez, demonstraram não ter interesse em brincar com A2, apesar de cuidarem dele.

\section{Aluno 3}

A3 era um menino de 11 anos, estatura e corpo abaixo da média para a idade, apresentando grau elevado de dificuldades de aprendizagem, de acordo com o diagnóstico cognitivo feito pela escola. Estava numa classe com 28 alunos (17 meninos e 11 meninas), com idade entre 6 e 14 anos, havendo outras três crianças portadoras de necessidades educativas especiais.

Na avaliação sociométrica, A3 foi classificado como rejeitado, obtendo nove escolhas negativas entre seus 27 colegas, em que apenas cinco justificaram sua rejeição, alegando como motivos o excessivo comportamento motor, a inadequação social e a falta de repertório acadêmico de A3. 


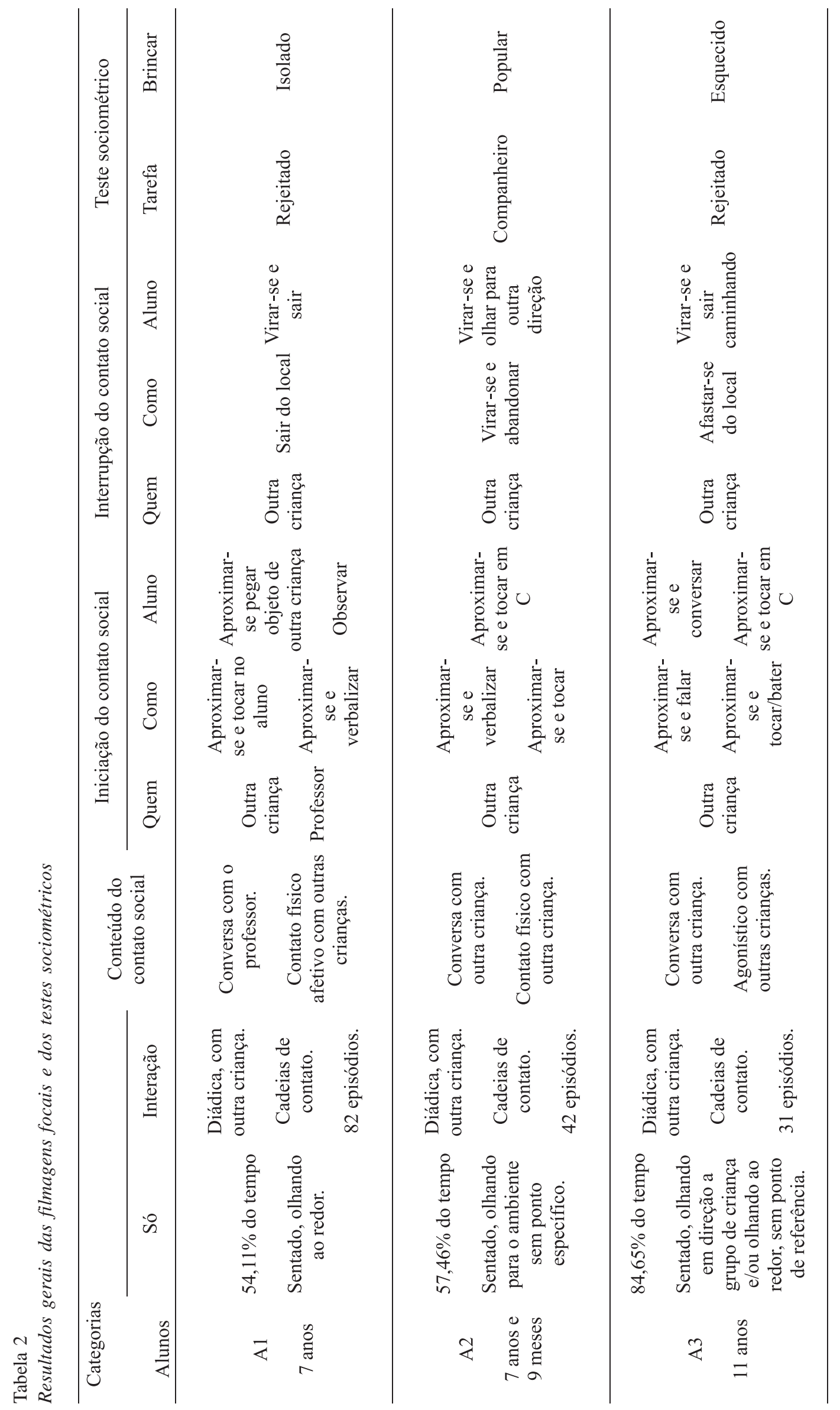


Nas preferências para brincar, encontrava-se na categoria dos esquecidos pela turma.

Durante as cinco sessões de observação no recreio (64 minutos e 23 segundos), A3 passou sozinho 84,6\% (54 minutos e 15 segundos) do tempo, sentado olhando em grupo de crianças brincando, outra parte do tempo (30\%) ficou sentado olhando ao redor, sem se fixar a nenhum ponto específico.

Quando interagiu (15,6\% do tempo), foi com os colegas, em díade. Seus episódios interativos duraram, em média, 19,12 segundos (cadeias de contato), em que ficava conversando com os colegas. Estes, além de fazer contato físico, mantiveram contato agonístico com A3, agredindo e instigando-o em sete episódios. Os colegas não brincaram com A3. Desse modo, os contatos interativos, na maioria das vezes, foram iniciados por outra criança $(80,6 \%)$ que se aproximava e conversava com A3.

Os poucos episódios interativos que ocorreram foram interrompidos principalmente pelo próprio A3 (74,1\%), que se afastava do colega (62,5\%) ou olhava para outra direção (25\%). Os colegas interrompiam o contato (25,8\% dos episódios) simplesmente afastando-se de A3 (56,5\%) ou virandose e ficando de costa para ele (26\%).

Os dados da observação foram coerentes com aqueles obtidos pelo teste sociométrico, indicando que A3 quase não interagia com seus colegas. Estes, por sua vez, demonstraram relutância em brincar ou fazer tarefas escolares com ele. Esses dados apontam a necessidade de se trabalhar com os colegas de A3 para melhorar a socialização, além de uma intervenção com ele próprio, na área de habilidades sociais, na medida em que poderá melhorar sua posição diante da turma.

\section{Discussão}

Os resultados do teste sociométrico mostraram que os alunos portadores de necessidades educativas especiais são aceitos com menos freqüência e são mais rejeitados do que seus companheiros de turma de classes regulares. Esta interpretação se mostra coerente com dados de Ray (1985), que também identificou que as crianças deficientes ou incapacitadas são menos aceitas socialmente por professores e colegas. Os resultados também mostraram que a rejeição está intimamente ligada à percepção que os alunos têm dos comportamentos, considerados como inadequados pelos colegas, emitidos pelas crianças com necessidades especiais. Tal fato foi constatado por Robert e Zubrick (1993) a respeito da influência desses comportamentos sobre a posição social dos alunos com necessidades educativas especiais.

Os dados sociométricos mostraram que os alunos focais não eram totalmente aceitos, nem estavam integrados, confirmando os resultados de Ausubel, Novak e Hanesian (1978) e de Gresham (1982). Esses autores alertam que não é a simples entrada da criança portadora de necessidades especiais na escola regular que garantirá ser beneficiada. Por outro lado, esses resultados não confirmam a argumentação de
Guralnick, Connor, Hammomd, Gottmam e Kinnish (1995), de que ambientes integradores dão mais suporte às interações entre companheiros do que as escolas especiais.

Destacam-se os dados sociométricos relativos ao aluno focal 2, que foram uma exceção. Ele ficou bem posicionado nas escolhas, não tendo sido escolhido negativamente por nenhum dos seus companheiros de classe. Uma explicação possível talvez esteja no fato do aluno focal 2 já ter estudado com a maioria dos alunos que compõem a sua classe. Entretanto, essa preferência identificada pelo teste sociométrico não se confirmou fora da sala de aula, fato este previsível a partir da constatação de Ladd, Musson e Miller (1984), de que a integração física, por si só, não garante a formação de ligações mais profundas.

Outra forma de explicar essa discrepância é considerar que, segundo Carvalho, Mussatti e Shavitt (1984), na escolha sociométrica são indicadas as "crianças que se destacam no grupo de alguma maneira, mais do que crianças com quem o sujeito interage de forma particularmente freqüente" (p. 40). Essas autoras consideram, ainda, que as crianças mostram mais seus conceitos a respeito dos colegas do que seu comportamento, ao serem avaliadas por testes sociométricos.

Os resultados dos testes sociométricos se mostraram coerentes com a afirmação de Deldime e Vermeulen (1999) de que as escolhas tendem a ser baseadas em estruturas simples, composta de duplas em que uma criança escolhe a outra, podendo ser feita em função das próprias necessidades das crianças e também em função do caráter estético. Este fato foi verificado, principalmente, em relação aos alunos 1 e 3 , nas justificativas dadas pelos colegas para sua não escolha, como por exemplo, "Porque ele não sabe brincar. Ele não sabe fazer dever também”.

Com base no exposto, observa-se que o teste sociométrico pode ser um excelente instrumento para o estudo das relações sociais de crianças com seus companheiros de classe; porém, nota-se a necessidade do uso de outros instrumentos para uma melhor compreensão dessas relações nas suas particularidades.

Ao observar as atividades dos alunos-foco durante o recreio, encontraram-se dados semelhantes quanto às condições vivenciadas. De certo modo, as observações corroboram os dados sociométricos dos alunos 1 e 3: estes passaram a maior parte do seu tempo sozinhos. Observou-se, também, de um modo geral, que as interações dos alunos 1, 2 e 3 foram diádicas.

A dificuldade de estabelecer contato social desses alunos pode ser deduzida a partir da análise dos dados sobre quem e como iniciava esses contatos: a maior parte dos contatos foi iniciada pelos colegas (média de 63,3\%); que se aproximavam e tocavam ou iniciavam a conversa. Com o aluno focal 3, particularmente, o início da interação se dava de forma antagonística, ou seja, os colegas aproximavam e o agrediam fisicamente.

Pode-se argumentar, entretanto, que os resultados dos contatos sociais efetivados pelos alunos focais 2 e 3 não são 
diferentes quando comparados com seus colegas. Ou seja, estes alunos iniciavam os contatos dirigindo-se aos colegas, aproximando-se, tocando e/ou conversando, e tinham estratégias semelhantes aos colegas para encerrar os contatos. O contrário ocorreu com a finalização dos contatos, em que 45,4\%, em média, dos episódios foram encerrados pelos alunos focais, sendo o sujeito 3 o que mais interrompeu os contatos (74,2\% dos seus episódios interativos). Particularmente, o aluno focal 1 mostrou ser inadequado ao iniciar os contatos sociais (aproximava-se e tirava objeto de outras crianças). Por apresentar um quadro de deficiência de linguagem e distúrbio neurológico, ele tinha uma relação diferenciada com a professora, uma vez que esta o acompanhava durante todo o tempo de recreio, interferindo, por vezes, no desenvolvimento de suas interações. Esta proximidade verificada em relação à professora, de acordo com Aranha (1991), pode influenciar o ritmo das aquisições de reorganizações qualitativas e na freqüência com que as crianças interagem.

Analisando com Harris (1995, 1999), pode-se considerar que essa rejeição ao estranho ou diferente faz parte do processo de formação de grupos, em que a categorização e a autocategorização atuam de forma a facilitar ou dificultar a aceitação no grupo. As diferenças comportamentais e físicas dos alunos em relação a seus colegas dificultam a assimilação no grupo, acentuando até o contraste entre eles. E isso ocorre porque os grupos tendem a atuar em direção à coesão, simetria e estabilidade, desenvolvendo um conjunto de critérios e regras consideradas aceitáveis para que sejam seguidas por seus membros.

Do mesmo modo, Turner (1984) salienta que a afiliação ao grupo acarreta uma reação por parte de seus membros. Em face a isso, pode-se pensar, com base em Harris $(1995,1999)$ e Turner (1984), que a dificuldade de contato dos alunos com seus colegas está tanto na aceitação como na identificação com o grupo. Não é só pela proximidade que alguém se acha pertencendo ao grupo, ele tem de se identificar com este, pois é esse o processo básico de formação do grupo. Reside aí, então, a importância do parceiro no desenvolvimento e para a aceitação desses alunos no grupo, fazendo com que este se perceba de algum modo semelhante, diminuindo o preconceito e aumentando a auto-estima.

Um outro aspecto que pode explicar essa dificuldade de relacionamento com os colegas está no fator tempo de exposição desses alunos a situações sociais mais amplas, cuja baixa freqüência acaba por levá-las a agir estereotipadamente, reforçando as diferenças existentes entre eles.

Com essa análise, percebe-se que esses alunos encontram-se incluídos fisicamente, mas não social e emocionalmente, dados esses consistentes com aqueles identificados na literatura desde a década de 50 do século XX (Gresham, 1982; Siperstein, Leffert \& Widaman, 1996).

Os resultados desta pesquisa mostram que o processo de desenvolvimento das interações entre os alunos portadores de deficiência e seus colegas de classe regular se dá de forma bastante semelhante. Não diferem quanto às estruturas, mas no ritmo e na forma de como os alunos portadores de necessidades especiais buscam e mantêm esta relação. Sendo, assim, considera-se que mudanças na educação, no sentido de buscar a inclusão desses alunos no ambiente de ensino regular, podem ser benéficas para o amadurecimento e desenvolvimento não só desses alunos, mas também daqueles sem necessidades educativas especiais. Cabe ressaltar, porém, que a questão não é apenas incluir, mas, como incluir. É necessário que, na prática, seja adotada uma política educacional que promova mudanças curriculares, efetivando a participação dos pais no processo de inclusão, instrumentalizando as escolas, capacitando e apoiando os profissionais que lidam com essas crianças, como alertam Bishop (s/d) e Marchesi e Martín (1995). Uma conseqüência desse fato reside na dificuldade em desenvolver nessas crianças competências sociais e cognitivas, que serão úteis no decorrer de sua vida. Habilidades essas, que, se não aprendidas no devido tempo, poderão acarretar desajustes sociais, reafirmando, assim a condição de deficiente.

A intervenção junto aos alunos deficientes não é suficiente; concomitantemente, faz-se necessário a intervenção junto aos colegas que estarão próximas delas, de modo a assegurar uma real inclusão. A análise da aceitação e do desenvolvimento das interações sociais de alunos portadores de necessidades especiais por seus colegas de escola contribuem, não somente para uma avaliação das conseqüências sociais para os estudantes em ambiente inclusivo, mas também para auxiliar no esboço de uma prática educacional inclusiva que promova a interação e aceitação social de todos os estudantes.

Cabe, ainda, enfatizar que o sistema utilizado por Aranha (1991), usado como base para a presente investigação, mostrou-se eficaz para analisar os padrões interativos entre estudantes com necessidades educativas especiais e seus companheiros de classe.

Para finalizar, convém salientar a necessidade de outras pesquisas nesse campo para se obter uma visão ampla do processo de inclusão, permitindo compreender as contradições que permeiam a prática da educação inclusiva. Não se pode ignorar a importância dos professores no processo de inclusão, por lidarem diretamente com os alunos portadores de necessidades educativas especiais, sendo os agentes mais eficazes no processo de inclusão.

\section{Referências}

Aranha, M. S. F. (1991). A interação social e o desenvolvimento de relações interpessoais do deficiente em ambiente integrado. Tese de doutorado nãopublicada, Universidade de São Paulo, São Paulo.

Aranha, M. S. F. (1994). A integração social do deficiente: análise conceitual e metodológica. Comunicação apresentada na XXIV Reunião Anual da Sociedade de Psicologia de Ribeirão Preto, Ribeirão Preto, São Paulo.

Arns, F. (1992). Integração é a conseqüência da realização dos direitos. Revista Integração, 4 (9), 2-3.

Ausubel, D. P., Hanesian, H., \& Novack, J. D. (1978). Psicologia educacional. Rio de janeiro: Interamerican. 
Batista, C. G. (1980). Elaboração de um catálogo de comportamentos motores observados na interação entre pais e filhos. Psicologia, 6(3), 47-81.

Bishop, V. E. [s/d] Educational inclusion: premise, practice, and promise. Anais da X World Conference of International Council for Education of People with Visual Impairment.

Bonow, I. W. (1972). Psicologia educacional e desenvolvimento humano: fundamentos psicossociais da educação. Manual de trabalhos práticos. São Paulo: Nacional.

Brasil, Senado Federal. (1988) Constituição da República Federativa do Brasil: texto constitucional promulgado em 5 de outubro de 1988. Brasília: Senado Federal, Subsecretaria de Edições Técnicas.

Brasil, Secretaria de Educação Especial. (1994) Política Nacional de Educação Especial: Livro 1. Brasília: MEC/SEESP.

Bueno, J. G. S. (1991) Educação Especial Brasileira: A Integração/Segregação do Aluno Diferente. Tese de doutorado não-publicada, Pontifícia Universidade Católica de São Paulo, São Paulo.

Cardoso, M. C. de F. (1992). Integração educacional e comunitária. Revista Brasileira de Educação Especial, 1(1), 89-99.

Carvalho, A. M. A. (1989). Brincar juntos - natureza e função da interação entre crianças. In C. Ades (Org.), Etologia de animais e de homens (pp. 199-210). São Paulo: Edicon/EDUSP.

Carvalho, A. M. A., Musatti, M., \& Shavitt, E. (1984). Amizade entre crianças - um estudo sobre algumas relações entre comportamento interativo e escolha sociométrica. Psicologia, 10(3), 27-41.

Carvalho, R. E. (1994). Panorama internacional da integração: enfoque nacional. Revista Integração, 5(11), 9-13.

Deldime, R., \& Vermeulem, S. (1999). O desenvolvimento psicológico da criança. Bauru, SP: EDUSC.

Espírito Santo. (1989). Constituição (pp. 199-210). Vitória, ES: Assembléia Legislativa.

Figueiredo, M. (1990). Integração social dos portadores de deficiências. Revista Integração, 3(5), 17-18.

Glat, R. (1989) Por que formar profissionais em educação especial? Revista integração, 2(4), 11-12.

Glat, R. (1994) A integração dos portadores de deficiências: uma questão psicossocial. [Resumo]. In Sociedade de Psicologia (Org.), XXIV Reunião anual da Sociedade de Psicologia Ribeirão Preto. Resumos. Ribeirão Preto: Autor.

Glat, R. (1998). A integração social dos portadores de deficiências: uma reflexão. Rio de Janeiro: Sette Letras.

Gresham, F. M. (1982). Misguided mainstreaming: the case for social skills training with handicapped children. Exceptional Children, 48, 422-433.

Guralnick, M. J., Connor, R. T., Hammond, M., Gottman, J. M., \& Kinnish, K. (1995). Immediate effects of mainstreamed settings on the social interactions and social integration of preschooler children. Journal of Mental Retardation, 100(4), 359-377.

Harris, J. R. (1995) Where is the child's environment? A group socialization theory of development. Psychological Review, 102(3), 458-489.

Harris, J. R. (1999). Diga-me com quem anda... . Rio de Janeiro: Objetiva.

Jannuzzi, G. S. de M. A. (1992). Oficina obrigada e a "integração” do “deficiente mental”. Revista Brasileira de Educação Especial, 1(10), 51-63.

Kupersmidt, J. B., Coie, J. D., \& Dodge, K. A. (1990). The role of peer relationships in the development of disorder. In S. R. Asher \& J. D. Coie (Orgs.), Peer rejections in childhood (pp. 17-59). Nova York: Cambridge University Press.

Ladd, G., Musson, H. L., \& Miller, J. K. (1984). Social integration of deaf adolescents in secondary level mainstreamed programs. Exceptional Children, 50(5), 420-428.

Lima, L. O. (1969). Treinamento em dinâmica de grupo no lar, na empresa, na escola. Petrópolis, RJ: Vozes.
Mantoan, M. T. E. (1988). Compreendendo a deficiência mental: novos caminhos educacionais. São Paulo: Scipione.

Mantoan, M. T. E. (Org.). (1997). A integração de pessoas com deficiência: contribuições para uma reflexão sobre o tema. São Paulo: Memnom, SENAC.

Marchesi, A., \& Martín, E. (1995). Da terminologia do distúrbio às necessidades educativas especiais. In C. Coll, A. Marchesi, \& J. Palacios (Orgs.), Desenvolvimento psicológico e educação: Vol. 3. Necessidades educativas especiais e aprendizagem escolar (pp. 7-23). Porto Alegre: Artes Médicas.

Mazzota, M. J. S. (1982). Fundamentos de Educação Especial. São Paulo: Pioneira.

Mendes, E. G. (1994). Reflexão sobre a experiência de Santa Catarina. Revista Integração, 5(12), 5-16.

Meyer, L., Cole, D. A., Macquarter, R. E., \& Reichle, J. (1990). Validation of the assesment of social competence for children and young adults with developmental disabilities. Journal of the Association for Persons with Severe Handicaps, 15(2), 57-68.

Monteiro, R. (1993). Técnicas fundamentais do psicodrama. São Paulo: Brasiliense.

Morin, E. (1979). O enigma do homem - para uma nova antropologia. Rio de Janeiro: Zahar.

Nunes, F., \& Santos, L. (1988). A integração da criança deficiente: valorização do conhecimento produzido em Educação Especial [Resumo]. In Associação Brasileira para o Estudo Científico da Deficiência Mental (Org.), Seminário Alternativas de Integração da Pessoa Deficiente Mental. Resumos. Rio de Janeiro: Autor.

Omote, S. (1994). A integração do deficiente: um pseudo problema. Comunicação apresentada na XXIV Reunião Anual da Sociedade de Psicologia de Ribeirão Preto, Ribeirão Preto, SP.

Pereira, O. S. (1990). Educação integrada: somos todos responsáveis. Revista Integração, 3(6), 16-17.

Piotto, D. C., \& Rubiano, M. R. B. (1999). Amizade entre crianças pequenas: análise da interação de pares preferenciais na creche. Psico, 30(1), 109-129.

Ray, B. M. (1985). Measuring the social position of the mainstreamed handicapped child. Exceptional Child, 52(1), 57-62.

Roberts, C., \& Zubrick, S. (1992). Factors influencing the social status of children with mild academic disabilities in regular classrooms. Exceptional Children, 59(3), 192-202.

Saint-Laurent, L. (1997) A educação de alunos com necessidades especiais. In M. T. E. Mantoan (Org.), A integração de pessoas com deficiência: uma contribuição para uma reflexão sobre o tema (pp. 67-76). São Paulo: Memnon, SENAC.

Sassaki, R. K. (1997). Inclusão. Construindo uma sociedade para todos. Rio de Janeiro: WVA.

Silva, J. M. (1979). A posição e a função relativa de cada pessoa num grupo sociometria. In J. M. Silva (Org.), Um programa de dinâmica de grupo e relações humanas. Brasília.

Siperstein, G. N., Leffert, J. S., \& Widaman, K. (1996). Social behavior and the social acceptance and rejection of children with mental retardation. Education and Training in Mental Retardation and Developmental Disabilities, 31(4), 271-281.

Strain, P. S., \& Shores, R. E. (1983). A reply to “misguided mainstreaming”. Exceptional Children, 50(3), 271-273.

Thomas, G., Walker, D., \& Webb, J. (1998). The making of the inclusive school. Nova York: Routledge.

Turner, J. (1984). Social identification and psychological group formation. In H. Tajfel (Org.), The social dimension, Vol. II (pp. 518-538). Cambridge: Cambridge University Press.

Werneck, C. (1997). Ninguém mais vai ser bonzinho, na sociedade inclusiva. Rio de Janeiro: WVA. 
Marcus Welby Batista é mestre em Psicologia pela Universidade Federal do Espírito Santo. Endereço para correspondência: Av. Santo Antônio, 1354, Santo Antônio; Vitória, ES; CEP 29025-000. Fone: (27) 32233593. E-mail: marcusbatista@hotmail.com

Sônia Regina Fiorim Enumo, doutora em Psicologia Experimental pela Universidade de São Paulo, é professora no departamento de Psicologia Social e do Desenvolvimento da Universidade Federal do Espírito Santo. Endereço para correspondência: Av. Nossa Senhora da Penha, 2432, apto. 1205; Edif. Angra dos Reis, Santa Luiza; Vitória, ES; CEP 29045-909. Fone: (27) 3227-7318. E-mail: enumosrf@npd.ufes.br 